\title{
Diameter of Renal Corpuscles of Bangladeshi People in Different Age Groups
}

\author{
Shibani Banik ${ }^{1}$, Fahima Aktar ${ }^{2}$ \\ Received: May 15, 2013 Accepted: November 3, 2013
}

\begin{abstract}
Background: The functional unit of the kidney is the uriniferous tubule which consists of a nephron and a collecting duct. The nephron consists of two components - the renal corpuscle and the renal tubule. Blood is filtered by the renal corpuscle and the filtered substance is poured into the renal tubule and collecting duct. There are about two million renal corpuscles in each kidney. Renal diseases that involve the nephron mostly affect renal corpuscles. Due to aging there is gradual increase in size of renal corpuscle with subsequent decrease of renal function. It is essential to know the functional status of an aged kidney for management of kidney diseases or renal transplantation. As there are very few known studies about the diameter of renal corpuscle in Bangladeshi people, we designed this study. Objective: To find out the difference in diameters of renal corpuscles in micrometer in the stained section of kidneys in different age groups. Materials and Methods: This is an observational type of study carried out in the department of Anatomy of Sir Salimullah Medical College (SSMC) from January 2004 to December 2005. The study was performed on 50 pairs of human kidneys. All these samples were collected from the bodies of unclaimed autopsied individuals from the morgue of the departments of Forensic Medicine of Dhaka Medical College and SSMC. The collected samples were divided into three groups - Group A (6-20 yrs), Group B (21-35 yrs) and Group C (36-65 yrs). Results: The diameters of renal corpuscles were found $157.10 \pm 5.58$ and $154.25 \pm 8.90$ micrometers in the right and left kidneys of Group A, 159.04 \pm 8.55 and $159.18 \pm 9.89$ micrometers in the right and left kidneys of Group $B$ and $176.58 \pm$ 6.69 and $178.35 \pm 8.84$ micrometers in the right and left kidneys of Group $C$. There was significant difference of diameters between Group $A$ and Group $C$ and between Group B and Group C. Conclusion: The diameter of renal corpuscle increases significantly with age after 35 years.
\end{abstract}

Key words: Kidney, Renal corpuscle, Age

J Enam Med Col 2014; 4(1): 36-38

\section{Introduction}

The kidneys are vital in maintaining homeostasis of the body. They regulate blood pressure, blood composition and fluid volume of the body, produce urine and maintain acid-base balance. ${ }^{1}$ In Bangladesh about 6 to 8 million people are suffering from kidney diseases. Most of the kidney diseases are chronic glomerulonephritis, diabetic nephropathy, hypertensive nephrosclerosis, obstructive uropathy and congenital or familial kidney diseases. ${ }^{2}$ Aging is a biologic process from which no living being is exempted and the universal effect of aging is the gradual loss of functioning cells from many organs and tissues. The biological price of aging includes progressive deterioration of function and structure. After the age of 30 years glomerular filtration and renal blood flow rates decline in a linear fashion. ${ }^{3}$ Renal mass similarly declines and the incidence of sclerotic glomeruli increases with advancing age.

1. Associate Professor, Department of Anatomy, Dhaka National Medical College, Dhaka

2. Professor, Department of Anatomy, Enam Medical College, Savar, Dhaka

Correspondence Shibani Banik,Email: banik85@gmail.com 
Accordingly, the aging kidney is at high risk of eventual failure when functioning nephron number is further reduced by acquired renal diseases. ${ }^{4}$ Renal corpuscle represents the initial part of a nephron. In man the renal corpuscles are variable in size, diameter ranging from 150-250 $\mu \mathrm{m}$. It has been observed by various workers that diameter of renal corpuscles varies with age and gradually increases along with age. ${ }^{5,6}$ In our country there are very few studies regarding microscopic structure of this gland. For this reason present study was designed to observe the microscopic diameter of renal corpuscle in Bangladeshi people in relation to age.

\section{Materials and Methods}

This is an observational, descriptive type of study carried out in the department of Anatomy in Sir Salimullah Medical College (SSMC), Dhaka from January 2004 to December 2005. The study was performed on 50 pairs of human kidneys. All these specimens were collected from bodies of unclaimed autopsied individuals from the morgue of the departments of Forensic Medicine of Dhaka Medical College and SSMC. The specimens were divided into three age groups according to the study of Darmedy et al. ${ }^{7}$ These were Group A (6-20 yrs), Group B (21-35 yrs) and Group C (36-65 yrs). Age of the subjects was determined approximately. The kidneys looked apparently healthy. The collected specimens were washed thoroughly with running tap water and were kept in $10 \%$ formaldehyde for preservation and fixation. Six pairs of kidneys were selected by random sampling method from each group. Slices of the tissues approximately $3 \mathrm{~mm}$ in thickness were taken from cortical regions. From these slices small rectangular pieces were taken for microtome section and subsequent processing and then stained with routine hematoxylin and eosin (H\&E) stain.

\section{Procedure of measurement of diameter of renal corpuscle}

For measurement of the diameter of corpuscle, 12 slides from six pairs of kidneys from each group were taken. Thus 36 slides were examined under $10 \times$ objectives. From each slide 5 renal corpuscles were chosen. Total 180 different Malpighian corpuscles were observed for measuring diameter of corpuscles (60 from each group). The diameter of the corpuscles was measured by using an ocular micrometer. As the Malpighian corpuscles were not perfectly round or oval in shape, two measurements were taken from each corpuscle. One measurement was taken at the maximum transverse diameter of the corpuscle and another one at direction perpendicular to the first one. Thus the transvertical diameters of the corpuscles were measured by taking the average of two diameters taken at right angles to each other. Finally, mean of the average measures was calculated for each kidney in all groups and mean diameters were compared between groups. Statistical analyses were done by Student's unpaired $t$ test using Windows Version 12.0.

\section{Results}

Table I shows the mean $( \pm \mathrm{SD})$ diameters of renal corpuscles of both the kidneys. These were $157.10 \pm$ $5.58 \mu \mathrm{m}$ and $154.25 \pm 8.90 \mu \mathrm{m}$ in the right and left kidneys of Group A, $159.04 \pm 8.55 \mu \mathrm{m}$ and $159.18 \pm$ $9.89 \mu \mathrm{m}$ in the right and left kidneys of Group B and $176.58 \pm 6.69 \mu \mathrm{m}$ and $178.35 \pm 8.84 \mu \mathrm{m}$ in the right and left kidneys of Group C. The mean diameter of renal corpuscle was highest in Group C and lowest in Group A. There was no significant difference in diameter between Group A and Group B; but significant difference was found between Group A and Group C and between Group B and Group C. Fig 1 shows correlation of diameter of renal corpuscles with age. The diameter of renal corpuscles was found significantly increased with the increasing age $(\mathrm{p}<0.01)$ after 35 years. In Fig 2 photomicrographs of sections of kidney show that size of renal corpuscle is larger at the age of 51 years (B) than it is at the age of 24 years (A).

Table I: Diameter of renal corpuscles in different age groups

\begin{tabular}{|c|c|c|c|c|}
\hline \multirow[t]{2}{*}{ Groups } & \multicolumn{2}{|c|}{$\begin{array}{c}\text { Diameter of renal corpuscles }(\mu \mathrm{m}) \\
(\text { Mean } \pm \text { SD })\end{array}$} & \multicolumn{2}{|c|}{$P$ values } \\
\hline & Right Kidney & Left kidney & Right Kidney & Left kidney \\
\hline A & $157.10 \pm 5.58$ & $154.25 \pm 8.90$ & $\begin{array}{l}\text { A vs B } \\
0.65^{\mathrm{NS}}\end{array}$ & $\begin{array}{l}\text { A vs B } \\
0.386^{\mathrm{NS}}\end{array}$ \\
\hline B & $159.04 \pm 8.55$ & $159.18 \pm 9.89$ & $\begin{array}{l}\text { B vs C } \\
0.003^{* *}\end{array}$ & $\begin{array}{l}\text { B vs C } \\
0.005^{* *}\end{array}$ \\
\hline $\mathrm{C}$ & $176.58 \pm 6.69$ & $178.35 \pm 8.84$ & $\begin{array}{l}\text { A vs C } \\
0.003^{* *}\end{array}$ & $\begin{array}{l}\text { A vs C } \\
0.005^{* *}\end{array}$ \\
\hline
\end{tabular}

$P$ value obtained from unpaired Student's ' $t$ ' test $\mathrm{NS}=$ not significant, $* *=$ Significant at $\mathrm{p}<0.01$ 


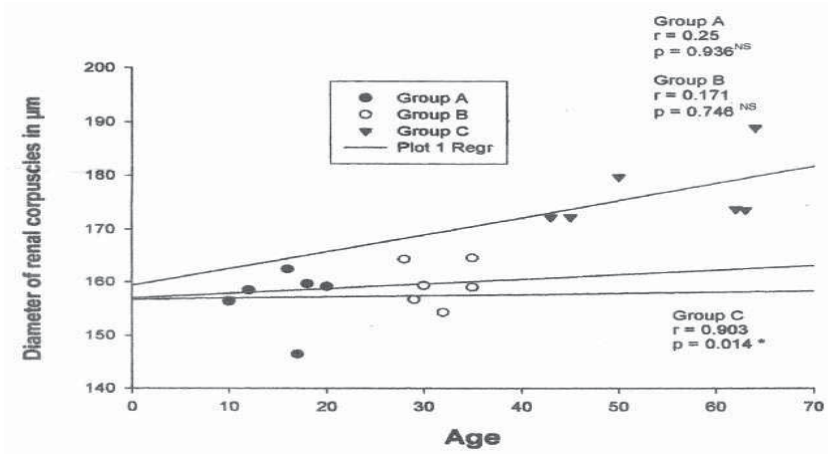

Fig 1. Correlation of diameter of renal corpuscles with age

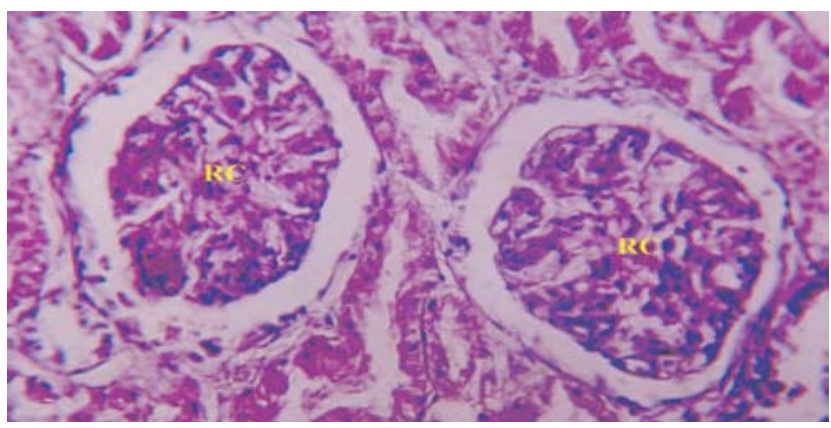

A

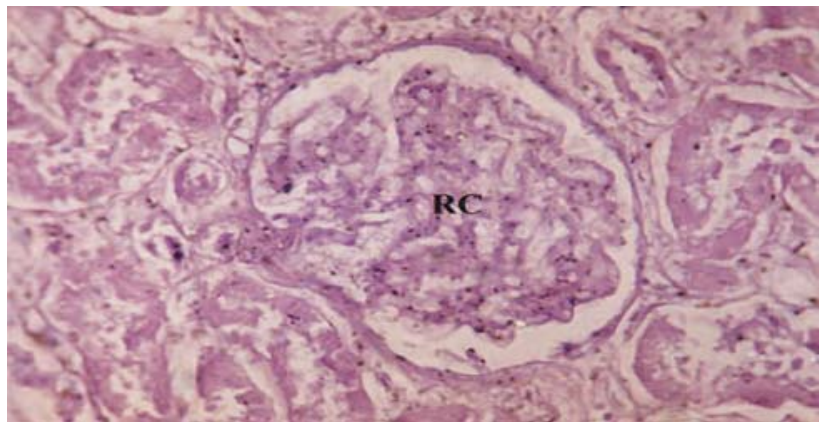

B

Fig 2. Photomicrographs of sections of kidneys showing the renal corpuscle (RC) (A, at 24 years; $\mathrm{B}$, at 51 years)

\section{Discussion}

Renal corpuscles are variable in size in relation to age. The size of the corpuscles gradually increases with the increase of age. It was also observed by Goyal $^{8}$ that the size of Malpighian or renal corpuscles is increased with advancing age or in senile kidneys. Cormack ${ }^{9}$ observed that the renal corpuscle is generally ovoid with a diameter of 150 $\mu \mathrm{m}$ to $250 \mu \mathrm{m}$. Dunnil et $\mathrm{al}^{10}$ observed that the renal corpuscles were small rounded masses, the average diameter being $0.2 \mathrm{~mm}$. In the present study all the histological sections were taken from cortical regions of the kidneys. In this study it was found that the diameter of renal corpuscles gradually increased with the increasing age; but it increased significantly $(p<0.01)$ after 35 years. The findings of the present study is similar to the findings of Zahed et al. ${ }^{11}$ Tauchi et $\mathrm{al}^{12}$ have also described that diameter of renal corpuscles increases with gradual increase in age.

The result of the present study will enrich the information pool on the histological status of kidneys in Bangladeshi population. However, further studies using larger sample size covering both sexes and wider age range using more advanced methods such as resin corrosive cast, imaging techniques or angiography are recommended.

\section{References}

1. Eroschenko VP. Urinary system. In: Atlas of histology with functional correlations. $17^{\text {th }}$ edn. Baltimore: Williams and Willkings Company, 1995: 243-256.

2. Rahman $\mathrm{MH}$. End stage renal failure and its present management in Bangladesh situation. Bangladesh Renal J 2002; 21: 32-33.

3. Anderson S, Brenner BM. Effect of aging on the renal glomerulus. Amer J. Med. 1986; 80: 435-437.

4. Anderson JE. Urinary system. In: Grant's atlas of anatomy. $8^{\text {th }}$ edn. London: Williams and Willkings Company, 1980: 2103-2110.

5. Dobyan DC, Bulger RE. Recent advances in renal morphology. Ann Rev Physiol. 1982; 44: 147-179.

6. Devis JC, Sheehan HL. Anatomy of pelvis in the rabbit kidney. J Anat. 1959; 93: 499-502.

7. Dermady EM, Offer J, Woodhouse MA. The parameters of the aging kidney. J Pathol. 1973; 109: 195-208.

8. Goyal VK. Changes with age in the human kidney. Exp. Gerontol. 1981; 17: 321-331.

9. Ham AW. Urinary system. In: Cormack DH (ed). Ham's histology. $9^{\text {th }}$ edn. Philadelphia: Lippincott Company, 1987: 568-587.

10. Dunnill MS, Halley W. Some observations on the quantitative anatomy of the kidney. J Pathol. 1973; 110(2): 113-121.

11. Zahed M. Gross and histological study of kidney in Bangladeshi people [M. Sc. Thesis]. Dhaka: University of Dhaka; 1990.

12. Tauchi C, Madsen KM. Anatomy of the kidney. In: Brenner BM, Rector (eds). The kidney. $7^{\text {th }}$ edn. London: Williams and Willkins Company, 1995: 1-88. 